\title{
Synthesis and 1D Chain Crystal Structure of Zinc(II) Terephthalate Complex: $\left[\mathrm{Zn}(\mathbf{t p})(\mathbf{p y})\left(\mathrm{H}_{\mathbf{2}} \mathrm{O}\right)\right]_{\mathrm{n}}$
}

\author{
Jungsook Kim, Uk Lee, ${ }^{\dagger}$ and Bon Kweon Koo* \\ Department of Chemistry, Catholic University of Daegu, Gyeongbuk 712-702, Korea. *E-mail: bkkoo@cu.ac.kr \\ ${ }^{\dagger}$ Department of Chemistry, Pukyong National University, Pusan 608-737, Korea \\ Received March 17, 2010, Accepted April 9, 2010
}

Key Words: Zn(II) complex, 1D chain, Crystal structure, Hydrogen bonding

Recently much attention has been paid to design and synthesis of metal-organic hybrid materials with fascinating network topologies $^{1-3}$ and potential applications as functional materials. ${ }^{4-6}$ The most commonly used strategy for designing such materials relies on the utilization of multidentate $\mathrm{N}$ - or O-donor ligands which have the capacity to bridge between metal centers to form polymeric structures. Hydrogen bonding and $\pi-\pi$ stacking have also been demonstrated to exert additional control over the coordination geometry of metal ions and over the generation of supramolecular polymers.

Terephthalate (tp), with versatile modes of coordination, is a suitable ligand for the design and construction of metal-organic coordination polymers which exhibit various topological structures. $^{7,8} 4,4^{\prime}$-Bipyridine (4,4'-bpy) is also an excellent ligand and a number of one-, two- and three-dimensional infinite metal4,4'-bpy frameworks have been generated. ${ }^{9-12}$ Although many interesting examples including the ligand combination of terephthalate and 4,4'-bipyridine have been reported, ${ }^{13-15}$ the development of synthetic routes to systems containing two or more different bridging ligands is much less well explored, and it is generally not yet possible to predict either the composition or structure of the product, much work is required for the rational design and synthesis.

In this context, we have been pursuing synthetic strategies for the preparation of non-interpenetrating open frameworks with variable cavities or channels, in which rod-like rigid spacers such as 4,4'-bpy and related species are chosen as building blocks. ${ }^{16-18}$ During studies aimed at constructing cavity containing rectangular two-dimensional networks using dicarboxylate ions, we have isolated two kinds of one-dimensional coordination polymers $-\left[\mathrm{Zn}(\text { terephthalate })(\text { pyridine })\left(\mathrm{H}_{2} \mathrm{O}\right)\right]_{\mathrm{n}}(\mathbf{1})$ and $\left[\mathrm{Zn}(\text { oxalate })(\text { pyridine })\left(\mathrm{H}_{2} \mathrm{O}\right)\right]_{\mathrm{n}}(2)$ - based upon terephthalate/ oxalate anion. We report here the synthesis and crystal structure of the one-dimensional polymeric compound $\mathbf{1}$, in which hydrogen-bonding and $\mathrm{C}-\mathrm{H}(\mathrm{tp}) \cdots \pi$-ring(py) interactions link the polymeric chains into a two-dimensional supramolecular network.

\section{Experimental Section}

All chemicals are commercially available and were used as received without further purification. Elemental analyses $(C$, H, N) were performed on a Carlo Erba EA-1106 Elemental Analyzer. Infrared spectra were recorded in the range from 4000 to $400 \mathrm{~cm}^{-1}$ on a Mattson Polaris FT-IR Spectrophotometer using $\mathrm{KBr}$ pellets. Thermogravimetric (TG) and differential thermal analysis (DTA) were performed on a Shimadzu DTG-60 instrument with a heating rate of $10^{\circ} \mathrm{C} \cdot \mathrm{min}^{-1}$. All reactions were carried out in $23 \mathrm{~mL}$ Teflon-lined stainless-steel autoclave. The vessels were filled approximately to $40 \%$ capacity. The initial and final $\mathrm{pH}$ of the reaction was measured using Sentron 1001 $\mathrm{pH}$ meter.

Preparation of $\left[\mathbf{Z n}(\mathbf{t p})(\mathbf{p y})\left(\mathbf{H}_{2} \mathrm{O}\right)\right]$ (1). A mixture of $\mathrm{Zn}\left(\mathrm{NO}_{3}\right)_{2}$. $6 \mathrm{H}_{2} \mathrm{O}(0.148 \mathrm{~g}, 0.5 \mathrm{mmol})$, terephthalic acid $(0.083 \mathrm{~g}, 0.5 \mathrm{mmol})$, 4,4'-trimethylenebipyridine (4,4'-tbp) (0.986 g, $0.5 \mathrm{mmol})$, pyridine ( $0.978 \mathrm{~g}, 12.4 \mathrm{mmol})$, and $\mathrm{H}_{2} \mathrm{O}(8 \mathrm{~mL}, 444 \mathrm{mmol})$ in the mole ratio 1.0:1.0:1.0:24.8:888 was placed in a $23 \mathrm{~mL}$ Teflon-lined Parr acid digestion bomb and heated for $7 \mathrm{~d}$ at $180{ }^{\circ} \mathrm{C}$ under autogenous pressure. After the mixture was removed from the oven and allowed to cool under ambient conditions for $3 \mathrm{~d}$., large colorless needles of 1 suitable for X-ray diffraction were isolated in $91 \%(0.150 \mathrm{~g})$ yield based on $\mathrm{Zn}$. Initial $\mathrm{pH}, 6.0$; final $\mathrm{pH}, 6.0$. Anal. Calcd. for $\mathrm{C}_{13} \mathrm{H}_{11} \mathrm{NO}_{5} \mathrm{Zn}$ : C, 47.81; H, 3.39; N, 4.29. Found: C, 46.88; H, 3.38; N, 4.22\%. IR (KBr pellet, $\mathrm{cm}^{-1}$ ): 3080(w), 1609(w), 1548(s), 1503(s), $1449(\mathrm{~m}), 1399(\mathrm{~s})$, 1370(s), 1309(m), 1214(w), 1019(w), 838(m), $737(\mathrm{~m}), 703(\mathrm{~m})$, 642(w).

Preparation of $\left[\mathbf{Z n}(\mathbf{o x})(\mathrm{py})\left(\mathbf{H}_{\mathbf{2}} \mathbf{O}\right)\right]$ (2). The synthesis of $\mathbf{2}$ was similar to that of 1 except that oxalic acid and 4,4'-bipyridine were used instead of terephthalic acid and 4,4'-tbp, respectively. Colorless crystals, but to get single crystal enough for X-ray diffraction was failed. Initial $\mathrm{pH}, 6.0$; final $\mathrm{pH}, 6.0$. Yield $83 \%$ $(0.110 \mathrm{~g})$ based on zinc. Anal. Calcd. for $\mathrm{C}_{7} \mathrm{H}_{7} \mathrm{NO}_{5} \mathrm{Zn}$ : C, 33.56; H, 2.82; N, 5.59. Found: C, 33.05; H, 2.92; N,5.30\%. IR (KBr pellet, $\left.\mathrm{cm}^{-1}\right)$ : 3053(w), 3036(w), 1661(w), 1597(s), 1535(m), 1410(m), 1367(w),1315(m), 1219(w), 1007(w), 804(m) 732(w), 629(w).

$\mathbf{X}$-ray structure determination. Single crystals of 1 was obtained by the method described in the above procedures. Structural measurement for the complex was performed on a Bruker SMART APEXII CCD ${ }^{19}$ diffractometer using graphite monochromatized Mo K $\alpha$ radiation $(\lambda=0.71073 \AA)$. A multi-scan absorption correction was applied using the SADABS program. ${ }^{19}$ The structures were solved by direct method and refined on $F^{2}$ by full-matrix least-squares procedures using the SHELXS 97 and SHELXL 97 programs, ${ }^{20}$ respectively. All non-hydrogen atoms were refined using anisotropic thermal parameters. $\mathrm{CH}$ Hydrogen atoms were included in the structure factor cal- 
Table 1. Crystal data and structure refinement for the complex of $\mathbf{1}$

\begin{tabular}{ll}
\hline \multicolumn{1}{c}{ Complex } & \multicolumn{1}{c}{$\mathbf{1}$} \\
\hline Empirical formula & $\mathrm{C}_{13} \mathrm{H}_{11} \mathrm{NO}_{5} \mathrm{Zn}$ \\
Formula weight & 326.62 \\
$\mathrm{~T}(\mathrm{~K})$ & $173(2)$ \\
$\lambda(\AA)$ & 0.71073 \\
Crystal system & monoclinic \\
Space group & $P 21 / n$ \\
$a(\AA)$ & $8.4297(5)$ \\
$b(\AA)$ & $9.1636(6)$ \\
$c(\AA)$ & $16.389(1)$ \\
$\beta\left(^{\circ}\right)$ & $91.444(1)$ \\
$V\left(\AA^{3}\right)$ & $1265.59(14)$ \\
$Z$ & 4 \\
$\mu($ mm & $-1)$ \\
$F(000)$ & 1.959 \\
$\theta\left(^{\circ}\right)$ & 664 \\
Absorption correction & 2.49 to 27.48 \\
Limiting indices & multi-scan $\mathrm{T}_{\min }=0.578, \mathrm{~T}_{\max }=0.819$ \\
Reflections collected & $-10 \leq h \leq 10,-9 \leq k \leq 11,-19 \leq l<21$ \\
Independent reflections & 7633 \\
Observed reflections $[I \geq 2 \sigma(I)]$ & $2856[R($ int $)=0.0225]$ \\
Goodness-of-fit on $F^{2}$ & 1.079 \\
$R_{1}[I \geq 2 \sigma(I)]$ & 0.0274 \\
$w R_{2}[I \geq 2 \sigma(I)]$ & 0.0647 \\
$R_{1}$ & 0.0347 \\
$w R_{2}$ & 0.0683 \\
Largest peak and hole $\left(\mathrm{e} \AA^{-3}\right)$ & 0.571 and -0.528 \\
&
\end{tabular}

culation at idealized positions by using a riding model, but not refined. Images were created with the ORTEP ${ }^{21}$ or DIAMOND program. ${ }^{22}$ The crystallographic data for complex $\mathbf{1}$ are listed in Table 1.

Crystallographic data for the structural analysis have been deposited at the Cambridge Crystallographic Data Center: 769348 (1). Copies of this information may be obtained free of charge from: The director, CCDC, 12 Union Road, Cambridge, CB2 1EZ, UK (Fax: +44-1223-336-003; E-mail: deposit@ccdc. cam.ac.uk or www: http://www.ccdc.cam.ac.uk).

\section{Results and Discussion}

The compounds were prepared from the reaction mixture of $\mathrm{Zn}\left(\mathrm{NO}_{3}\right)_{2} \cdot 6 \mathrm{H}_{2} \mathrm{O}$, terephthalic acid/oxalic acid, 4,4'-tbp/4,4'-bpy,
Table 2. Selected bond lengths $(\AA)$ and angles $\left({ }^{\circ}\right)$ for the complex of $\mathbf{1}$

\begin{tabular}{|c|c|c|c|c|}
\hline $\mathrm{Zn}-\mathrm{O} 1$ & $1.980(2)$ & $\mathrm{Zn}-\mathrm{O} 2$ & \multicolumn{2}{|r|}{$1.956(2)$} \\
\hline $\mathrm{Zn}-\mathrm{O} 4$ & $1.981(2)$ & $\mathrm{Cu}-\mathrm{N}$ & \multicolumn{2}{|r|}{$2.036(2)$} \\
\hline $\mathrm{O} 2-\mathrm{C} 6$ & $1.275(3)$ & O3-C6 & \multicolumn{2}{|r|}{$1.247(3)$} \\
\hline $\mathrm{O} 4-\mathrm{C} 10$ & $1.281(3)$ & $\mathrm{O} 5-\mathrm{C} 10$ & \multicolumn{2}{|r|}{$1.246(3)$} \\
\hline $\mathrm{O} 2-\mathrm{Zn}-\mathrm{O} 1$ & $115.63(7)$ & $\mathrm{O} 2-\mathrm{Zn}-\mathrm{O} 4$ & \multicolumn{2}{|r|}{$99.54(6)$} \\
\hline $\mathrm{O} 1-\mathrm{Zn}-\mathrm{O} 4$ & $113.86(7)$ & $\mathrm{O} 2-\mathrm{Zn}-\mathrm{N}$ & \multicolumn{2}{|r|}{$102.82(7)$} \\
\hline $\mathrm{O} 1-\mathrm{Zn}-\mathrm{N}$ & $106.38(7)$ & $\mathrm{O} 4-\mathrm{Zn}-\mathrm{N}$ & \multicolumn{2}{|r|}{$118.36(7)$} \\
\hline $\mathrm{O} 3-\mathrm{C} 6-\mathrm{O} 2$ & $123.3(2)$ & $\mathrm{O} 5-\mathrm{C} 10-\mathrm{O} 4$ & \multicolumn{2}{|r|}{$121.6(2)$} \\
\hline \multicolumn{5}{|c|}{ Specified hydrogen bonds (with esds except fixed and riding $\mathrm{H}$ ) } \\
\hline Donor-H $\cdots$ acc & tor $\quad \mathrm{D}-\mathrm{H}$ & $\mathrm{H} \cdots \mathrm{A}$ & $\mathrm{D} \cdots \mathrm{A}$ & D-H $\cdots A$ \\
\hline O1-H1A $\cdots$ & $0.82(4)$ & $1.85(4)$ & $2.670(2)$ & $179(4)$ \\
\hline $\mathrm{O} 1-\mathrm{H} 1 \mathrm{~B} \cdots$ & $0.77(4)$ & $1.93(4)$ & $2.703(2)$ & 173(3) \\
\hline $\mathrm{C} 3-\mathrm{H} 3 \cdots \mathrm{O}$ & 0.93 & 2.54 & $3.315(3)$ & 140.82 \\
\hline
\end{tabular}

pyridine, and $\mathrm{H}_{2} \mathrm{O}$ in the mole ratio $1.0: 1.0: 1.0: 24.8: 888$ by the hydrothermal reaction in good yield. The diamine $\left(4,4^{\prime}-\mathrm{tbp} /\right.$ 4,4 '-bpy) present in the initial reaction mixture was not found in the crystalline product. However, the compounds of $\mathbf{1}$ and $\mathbf{2}$ were not isolated in the absence of diamine. It is not uncommon for necessary reactants in hydrothermal processes to be absent from the product, while their specific role in nucleation or providing a repository of metal clusters remains elusive. ${ }^{17,23}$ Our first aim in this work was to obtain the 2D or 3D network MOF complexes which metal centers are bridged by the diamine and dicarboxylate anions. Unfortunately, attempts to obtain such materials by varying stoichiometry, temperature, and other reaction parameters proved to be generally unsuccessful.

Description of the structures. The structure of the complex 1 consists of zig-zag chain in which the zinc centers are bridged by two bis-monodentate centrosymmetric terephthalate ligands. The distorted tetrahedral geometry around the $\mathrm{Zn}$ (II) atoms is completed by a pyridine molecule coordinated by one nitrogen atom and one aqua ligand. Perspective view of the one-dimensional structure of the compound is shown in Fig. 1, whereas selected bond lengths and angles of the $\mathrm{ZnO}_{3} \mathrm{~N}$ chromophore are listed in Table 2. The dihedral angles between two consecutive terephthalate anions are about $10.0(2)^{\circ}$ and the $\mathrm{Zn} \cdots$ $\mathrm{Zn}^{\mathrm{ii}}(2-\mathrm{x}, 2-\mathrm{y}, 1-\mathrm{z})$ and the $\mathrm{Zn} \cdots \mathrm{Zn}^{\mathrm{i}}(1-\mathrm{x},-\mathrm{y}, 1-\mathrm{z})$ distances across these ligands ranges are 10.964(1) and 11.009(1) Å respectively, which are in good accordance with those previously reported for other terephthalate-bridged metal(II) complexes. ${ }^{9,24}$ In this

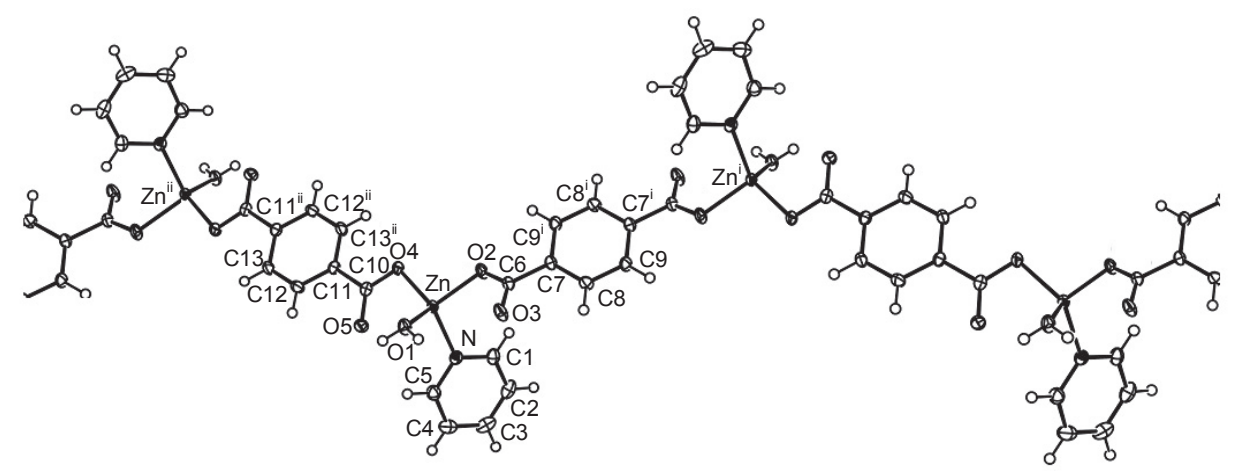

Figure 1. One-dimensional structure of 1 [Symmetry code: (i) 1-x, -y, 1-z; (ii) 2-x, 2-y, 1-z]. 


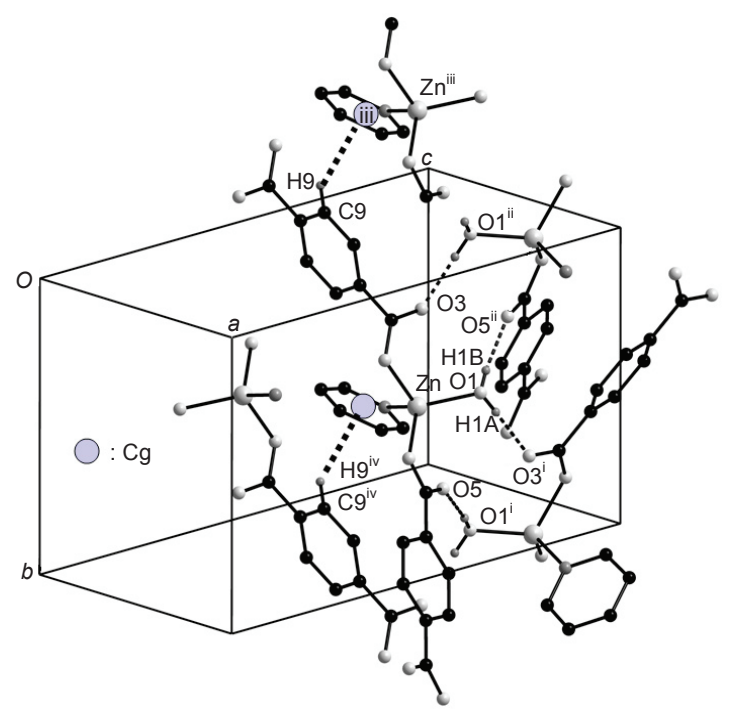

Figure 2. Hydrogen bonding and $\mathrm{C}-\mathrm{H} \cdots \pi$ interactions of $\mathbf{1} . \mathrm{Cg}$ is the centroid of the C1-C5, N ring [Symmetry codes: (i) 1.5-x, 0.5+y, 1.5-z; (ii) $1.5-\mathrm{x},-0.5+\mathrm{y}, 1.5-\mathrm{z}$; (iii) $\mathrm{x},-1+\mathrm{y}, \mathrm{z}$; (iv) $\mathrm{x}, 1+\mathrm{y}, \mathrm{z}]$.

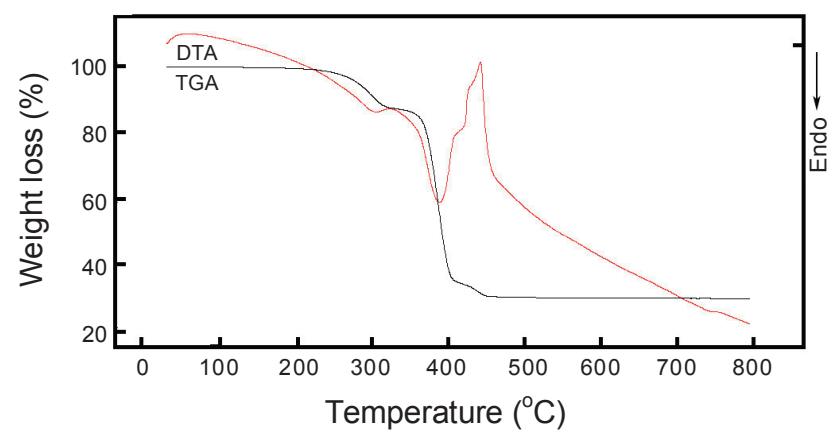

Figure 3. TGA curve of complex 2.

coordination polymer the pyridine ligands are trans to each other and the aqua ligands are also trans to each other.

The zig-zag chain structure is further extended by the intermolecular hydrogen bondings between the oxygen atom $(\mathrm{O} 1 \mathrm{w})$ from the coordinated water molecules and the uncoordinated carboxylate oxygen atoms (O3 and O5) [O1w-H1A ‥O3 (1.5-x, $0.5+\mathrm{y}, 1.5-\mathrm{z}) 2.670(2) \AA ; \mathrm{O} 1 \mathrm{w}-\mathrm{H} 1 \mathrm{~B} \cdots \mathrm{O} 5$ (1.5-x, -0.5+y, 1.5-z) 2.703(2) $\AA$ ] to form 2D layers, as illustrated in Fig. 2. Also, there is the non-covalent interactions between the central benzene ring of the terephthalate bridging ligand and pyridine ring $(\mathrm{C}-\mathrm{H}(\mathrm{tp}) \cdots \pi$-ring(py)). The distance between the terephthalate C9-H9 and the centroid of C1-C5, N ring is $2.66 \AA$.

The terephthalate ligand adopts simultaneously bis-monodentate coordination modes at both $\mathrm{Zn}$ ions. The $\mathrm{C}-\mathrm{O}$ bond distances and O-C-O bond angles are in the range of 1.246(3)1.281(3) $\AA$ and 121.6(2)-123.3(2) ${ }^{\circ}$, respectively. ${ }^{25}$ The O2-C6 bond length $(1.275(3) \AA)$ is somewhat longer than the O3-C6 of 1.247(3) $\AA$ as expected from oxygen $\mathrm{O} 2$ involved in coordination. The pyridine molecules are nearly planar [mean deviation is $0.003(2) \AA]$. The intra-ring $\mathrm{C}$-N [mean value $1.349(3) \AA$ ] and C-C [mean value 1.381(4) $\AA$ ] bond distances are as expected. $^{26}$
The IR spectra of the complexes exhibit the characteristic absorption bands of the dicarboxylate groups in the usual region at $1609(\mathrm{w})$ and $1548(\mathrm{~s}) \mathrm{cm}^{-1}$ for the antisymmetric stretching (1597(s) $\mathrm{cm}^{-1}$ for 2) and at 1399 (s), 1370 (vs) $\mathrm{cm}^{-1}$ (1367, 1315(s) $\mathrm{cm}^{-1}$ for 2) for symmetric stretching for 1. ${ }^{9,27}$ The peaks between 3080 and $3036 \mathrm{~cm}^{-1}$ and $1661-1400 \mathrm{~cm}^{-1}$ are attributable to the $\mathrm{C}-\mathrm{H}$, aromatic $\mathrm{C}-\mathrm{C}$, and $\mathrm{C}=\mathrm{N}$ stretching frequencies of the aromatic group. ${ }^{27}$ In addition, the peaks below $1219 \mathrm{~cm}^{-1}$ can be assigned to the $\mathrm{C}-\mathrm{H}$ in-plane or out-of plane band of the organic ligands.

Thermal properties of the complexes were observed in flowing $\mathrm{N}_{2}$ atmosphere from room temperature to $800{ }^{\circ} \mathrm{C}$ and the comlexes of $\mathbf{1}$ and $\mathbf{2}$ are totally decomposed in this range. For complex 1 , the first weight loss of $10.4 \%$ (calcd. 5.5\%) from 50 to $218{ }^{\circ} \mathrm{C}$ corresponds to the loss of one coordinated water molecule in the complex. However, the observed weight loss is higher than the calculated value. This indicates the dehydration process is overlapped with the pyridine decomposition step up to $326{ }^{\circ} \mathrm{C}$ (exp. $29.9 \%$, calcd. $29.7 \%$ ). The expected endothermic effect for dehydration is observed in the DTA maximum at $212{ }^{\circ} \mathrm{C}$. And then it undergoes successive exothermic processes leading to $\mathrm{ZnO}$ above $521{ }^{\circ} \mathrm{C}$ (exp. $22.5 \%$, calc. $24.9 \%$ ). The complex 2 is stable up to $108{ }^{\circ} \mathrm{C}$ and then it undergoes dehydration process for one coordinated water to $304{ }^{\circ} \mathrm{C}$ (exp. $10.5 \%$, calcd. $7.2 \%)$. The next decomposition process $(59.4 \%)$ occurring in the temperature range $304-465^{\circ} \mathrm{C}$ is assigned to the loss of all organic ligands (calcd. 66.7\%), resulting in a $\mathrm{ZnO}$ remnant (exp. $30.6 \%$, calcd. $32.48 \%$ ). The TGA curve of complex 2 is shown in Fig. 3.

In conclusion, by self-assembly reactions of $\mathrm{Zn}$ (II) ion, terephthalate/oxalate, 4,4'-bpy/4,4'-tbp, and pyridine ligands under hydrothermal conditions, two new $\mathrm{Zn}$ (II)-dicarboxylate complexes, $\left[\mathrm{Zn}(\mathrm{tp})(\mathrm{py})\left(\mathrm{H}_{2} \mathrm{O}\right)\right](\mathbf{1})$ and $\left[\mathrm{Zn}(\mathrm{ox})(\mathrm{py})\left(\mathrm{H}_{2} \mathrm{O}\right)\right](\mathbf{2})$ were isolated. The compound 1 consists of $1 \mathrm{D}$ zig zag chain of $[\mathrm{Zn}$ (py) $\left.\left(\mathrm{H}_{2} \mathrm{O}\right)\right]^{2+}$ units bridged by two terephthalate ligands. The compounds are a limited number of examples of polymeric structures based upon transition metals and the dicarboxylate ion. However, our interests lie in the design of cavity containing rectangular frameworks. We are currently in the process of attempting to construct rectangular frameworks based upon this coordination motif in which the coordinated pyridine is replaced by exo-bidentate bridging ligands.

\section{References}

1. Batten, S. R.; Robson, R. Angew. Chem. Int. Ed. 1998, 37, 1460.

2. Hagrman, P. J.; Hagrman, D.; Zubieta, J. Angew. Chem. Int. Ed. 1999, 38, 2638.

3. Carlucci, L.; Ciani, G.; Proserpio, D. Coord. Chem. Rev. 2003, 246, 247.

4. Batten, S. R.; Murray, K. S. Coord. Chem. Rev. 2003, 246, 103.

5. Ruben, M. ; Rojo, J.; Romero-Salguero, F. J.; Uppadine, L. H.; Lehn, J.-M. Angew. Chem. Int. Ed. 2004, 43, 3644.

6. Maspoch, D.; Ruiz-Molina, D.; Veciana, J. J. Mater. Chem. 2004, 14,2713

7. Mautner, F. A.; Vicente, R.; Louka, F. R. Y.; Massoud, S. S. Inorg. Chim. Acta 2008, 361, 1339.

8. Manna, S. C.; Konar, S.; Zangrando, E.; Okamoto, K.-I.; Ribas, J.; Chaudhuri, N. R. Eur. J. Inorg. Chem. 2005, 4646.

9. Tao, J.; Tong, M.-L.; Chen, X.-M. J. Chem. Soc., Dalton Trans. 2000, 3669. 
10. Fletcher, A. J.; Cussen, E. J.; Bradshaw, D.; Rosseinsky, M. J.; Thomas, K. M. J. Am. Chem. Soc. 2004, 126, 9750.

11. Zhao, X.; Liang, D.; Liu, S.; Sun, C.; Cao, R.; Gao, C.; Ren, Y.; $\mathrm{Su}, \mathrm{Z}$. Inorg. Chem. 2008, 47, 7133.

12. Zheng, Y.-Q.; Ying, E.-B. Polyhedron 2005, 24, 397.

13. Krishnan, S. M.; Supkowski, R. M.; LaDuca, R. L. Cryst. Growth Des. 2009, 9, 358.

14. Ghosh, A. K.; Ghoshal, D.; Zangrando, E.; Ribas, J.; Chaudhuri, N. R. Inorg. Chem. 2007, 46, 3057.

15. Setifi, F.; Bouchama, A.; Jean, S.-P.; Salaün, J.-Y.; Triki, S. Inorg. Chim. Acta 2006, 359, 3269.

16. Koo, B. K.; Kim, J.; Lee, U. Bull. Korean Chem. Soc. 2006, 27 , 2077.

17. Kim, J.; Lim, W. T.; Koo, B. K. Inorg. Chim. Acta 2007, 360, 2187.

18. Jung, E. J.; Lee, U.; Koo, B. K. Inorg. Chim. Acta 2009, 362, 1655.
19. Bruker (2009). APEXII and SADABS. Bruker AXS Inc., Madison, Wisconsin, USA.

20. Sheldrick, G. M. Acta Cryst. 2008, A64, 112.

21. Farrugia, L. J. J. Appl. Cryst. 1997, 30, 565.

22. Brandenburg, K. DIAMOND. Version 2.1. Crystal Impact GbR, Bonn, Germany. 1998.

23. Soghomonian, V.; Chen, Q.; Haushalter, R. C.; Zubieta, J.; O’Connor, C. J. Science 1993, 259, 1596.

24. Sun, D.; Cao, R.; Liang, Y.; Shi, Q.; Su, W.; Hong, M. J. Chem. Soc., Dalton Trans. 2001, 2335.

25. Qi, X.-L. Acta Cryst. 2009, E65, m135.

26. Catalina, R.-P.; Maria, H.-M.; Pablo, L.-L.; Francesc, L.; Juan, C.; Miguel, J. Inorg. Chem. 2000, 39, 3845.

27. Urko, G.-C.; Oscar, C.; Antonio, L.; Juan, P. G.-T.; Garikoitz, B.; Pascual, R. Cryst. Growth Des. 2006, 6, 1839. 